\title{
Social inequalities in traditional and emerging screen devices among Portuguese children: a cross-sectional study
}

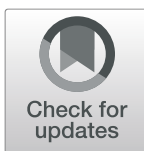

Daniela Rodrigues ${ }^{1,2^{*}}$ D , Augusta Gama ${ }^{1,3}$, Aristides M. Machado-Rodrigues ${ }^{1,4}$, Helena Nogueira ${ }^{1}$, Maria-Raquel G. Silva ${ }^{1,5}$, Vítor Rosado-Marques ${ }^{1,6}$ and Cristina Padez ${ }^{1,2}$

\begin{abstract}
Background: Children are often exposed to too much screen time but few studies have explored the use of old and new digital media among young children. This study assesses screen time, including traditional and mobile devices, in pre-school and elementary school-aged children, according to their gender, age, and socioeconomic position (SEP).

Methods: A total of 8430 children (3 to 10 years; $50.8 \%$ boys) from the north, center and south-central Portugal were included in the present study. Data was collected by a parental questionnaire during 2016/2017. Children's screen time (by media device, weekdays and at the weekend; calculated by mean minutes per day) were reported by parents. Analysis were carried to compare screen time by children's age, gender and family SEP (classified using father's educational degree).

Results: Daily screen time was high both in children aged 3 to 5 and 6 to 10 years - 154 min/day (95\% Cl: $149.51-$ 158.91) and $200.79 \mathrm{~min} /$ day (95\% Cl: 197.08-204.50), respectively - and the majority of children, independently of their gender, exceed the recommended $2 \mathrm{~h}$ /day of screen viewing. Children are still primarily engaging in screen time through television but the use of mobile devices, particularly tablets, were already high among 3 year-old children and increased with age. SEP was a negative predictor of screen time in the linear regression analysis, including after adjustment.

Conclusions: Considering the negative health impacts of excessive screen time, recognizing subgroups at risk of excessive screen time and identifying how each device is used according to age is fundamental to enable appropriate future interventions. The screen time in children aged 3-10 years is longer than the recommended, particularly among boys and in those children from lower SEP. Parents and policymakers should have in mind that children spend most of their screen time watching television but mobile devices are becoming extremely popular starting at a young age.
\end{abstract}

Keywords: Screen time, Television, Mobile devices, Socioeconomic inequalities, Children, Preschool, Portugal

\footnotetext{
* Correspondence: rodrigues1323@gmail.com

${ }^{1} \mathrm{CIAS}$ - Research Centre for Anthropology and Health, University of Coimbra,

Ed. São Bento, Calçada Martim de Freitas, 3000-456 Coimbra, Portugal

${ }^{2}$ Department of Life Sciences, University of Coimbra, Coimbra, Portugal

Full list of author information is available at the end of the article
}

(c) The Author(s). 2020 Open Access This article is licensed under a Creative Commons Attribution 4.0 International License, which permits use, sharing, adaptation, distribution and reproduction in any medium or format, as long as you give appropriate credit to the original author(s) and the source, provide a link to the Creative Commons licence, and indicate if changes were made. The images or other third party material in this article are included in the article's Creative Commons licence, unless indicated otherwise in a credit line to the material. If material is not included in the article's Creative Commons licence and your intended use is not permitted by statutory regulation or exceeds the permitted use, you will need to obtain permission directly from the copyright holder. To view a copy of this licence, visit http://creativecommons.org/licenses/by/4.0/ The Creative Commons Public Domain Dedication waiver (http://creativecommons.org/publicdomain/zero/1.0/) applies to the data made available in this article, unless otherwise stated in a credit line to the data. 


\section{Background}

In developed countries, many children live in a digitally enmeshed world. Time spent with screen media devices, including televisions (TV), computers (PC), electronic video games, smartphones and tablets, saturates the waking hours of young children [1-4]. Specifically, in recent years there has been a rapid uptake of mobile screen media devices among young children living in developed countries [5-7] and a recent study found that over onehalf of 3 year olds were given their own tablet [8].

Concerns about the effects of screen time on physical and biopsychological well-being among children have been raised [9-11]. Longer periods exposed to screens have been associated with higher risk of overweight and obesity due to the lack of physical activity and a negative impact on diet $[12,13]$. Other potential adverse effects of media exposure includes delayed cognitive and language development, attention deficits and behavioral problems such as violent behavior and aggression [1416]. Overall, children with higher screen time had increased risk of having a lower well-being, [17] and obesity, depression and anxiety have also been found associated with the use of newer technologies, such as smartphones [18-20]. Studies like those prompted authorities to recommend limits for children's daily screen: less than $1 \mathrm{~h}$ per day for children aged 2 to 5 years and less than $2 \mathrm{~h}$ per day for older children $[3,21,22]$. Moreover, the American Academy of Pediatrics [21] encourage parents to develop a family media use plan specific for each family and each family member. However, worldwide, a significant proportion of children are not following the recommended exposure time [23-25].

It is critical to understand when and how young children make use of the different screen media. However, very few studies on screen time have included children below the age of 5 years and most of the findings were based on passive forms of technology prior to the widespread introduction of mobile and touch-screen formats $[26,27]$. In addition, identifying population groups with the highest risk of accumulating excessive screen time enables the appropriate targeting of intervention programs. To provide further information on this issue, this study aims to determine the patterns of use of traditional devices (e.g., TV, PC, and electronic video games) as well as emerging devices (e.g., tablet and smartphones) by Portuguese young children according to their gender, age and socioeconomic position (SEP).

\section{Methods}

\section{Participants}

Participants were children aged 3 to 10 years old from three of the largest Portuguese cities (Porto, Coimbra, and Lisbon, respectively located in the north, center and south-central of mainland Portugal) were invited to participate. Data were collected between November 2016 and April 2017 in 118 public and private schools. Participation rates were $60 \%$ in Porto, $58 \%$ in Coimbra and $67 \%$ in Lisbon.

\section{Variables collected}

This study is part of the national project "Inequalities in childhood obesity: the impact of the socioeconomic crisis in Portugal from 2009 to 2015". The purpose of the referred project is to gain an understanding on the Portuguese prevalence of obesity and to explore a number of possible-related behaviors, including sedentary activities.

The screen-viewing behavior of the children was assessed by parental questionnaires previously used in a similar population [28]. Questionnaires are the most common method to measure screen time, particularly in young children, and the literature suggests that a questionnaire with strong psychometric properties can be a useful tool that estimates screen ownership and time in a simple, fast, no-cost, and completely anonymous way. Specifically, parents were asked to report the average time per day that the child spent watching TV, playing electronic videogames, using the $\mathrm{PC}$, the tablet or a smartphone. Each device was accessed in a different question and separate responses were collected for weekend and weekday use given that previous research suggests that level of children's screen time may differ between weekdays and weekend [29]. Response options were none $=0$, less than $1 \mathrm{~h}$ per day (recoded as approximately $30 \mathrm{~min}$ ), $1 \mathrm{~h} / \mathrm{d}=60 \mathrm{~min}, 2 \mathrm{~h} / \mathrm{d}=120 \mathrm{~min}, 3 \mathrm{~h} / \mathrm{d}=$ $180 \mathrm{~min}, 4 \mathrm{~h} / \mathrm{d}=240 \mathrm{~min}$, and more than $4 \mathrm{~h} / \mathrm{d}$ (recoded as approximately $300 \mathrm{~min}$ ). Total screen time was determined by adding television, computer, video games, smartphone, and tablets use. Given the AAP recommendations for daily screen use [21] and considering that previous studies have found that, for children, $\geq 2 \mathrm{~h}$ daily TV viewing was associated with reduced physical and psychosocial health [30] and $<1 \mathrm{~h} / \mathrm{d}$ of video game playing was associated with positive psychosocial health [31], screen time was categorized into 1) less than $1 \mathrm{~h} / \mathrm{d}, 2$ ) between $1 \mathrm{~h} / \mathrm{d}$ and $2 \mathrm{~h} / \mathrm{d}$, and 3) $2 \mathrm{~h} / \mathrm{d}$ or more. Items referred to behaviors occurring outside of school hours but did not distinguished recreational from educational use.

Factors such as gender, age, parental education and occupation, and urbanization were collected. Father's and mother's educational level was based on the Portuguese Educational system - 9 years' education or less, 10-12 years' education (secondary level), and higher education - and grouped into three categories (low, medium, and high). Father's and mother's occupation was self-reported and later classified according to the Portuguese Classification of Occupation (CPP/2010), which provided ten groups, namely: 0) Armed Forces, 1) 
Managers, 2) Professionals, 3) Technicians and associate professionals, 4) Clerical support workers, 5) Service and sales workers, 6) Skilled agricultural, forestry and fishery workers, 7) Craft and related trades workers, 8) Plant and machine operators and assemblers, and 9) Elementary occupations [32]. Place of residence was reported by the parents and urbanization was classified according to the criteria of the Portuguese Statistical System [33]. Father education was used as a proxy measure to the socioeconomic position (SEP), as seen in previous studies, including in the Portuguese context, since the country does not have an official measure of this variable [34, 35].

\section{Ethical approval}

Prior to commencing the study, the protocol was approved by Direção Geral do Ensino (Portuguese Ministry of Education) and Comissão Nacional de Proteção de Dados (CNPD), the Portuguese Data Protection Authority (Authorization number 745/2017). All procedures were in accordance with the 1964 Helsinki declaration and its later amendments. Written informed consent was obtained from children's parents.

\section{Statistical analyses}

A descriptive analysis was done using the screen time for all 7 days of the week (mean minutes/day in each device) according to gender and SEP, using age as a continuous variable. Later, the sample was divided in two groups according to children's age: 3 to 5 years (preschool-aged) and 6 to 10 years (elementary school-aged children). Linear regression models with 3 steps were used to predict children's screen time according to socioeconomic position. Model 2 was adjusted for children's gender. Model 3, included the variable in previous model, plus mother's education, parental occupation and urbanization. Model 3 allowed us to explore the interactions of other socioeconomic indicators. The adjusted $\mathrm{R}$-square was determined at each step. A final analysis was done using the categorized screen time and possible statistical differences between age groups were calculated using chi-square tests. All analyses were performed in SPSS version 23 (IBM SPSS ${ }^{\circ}$ software) using a significance level of 0.05 .

\section{Results}

Among the 3 to 5 years old children $(n=1860), 52.6 \%$ were males and $47.4 \%$ were females. The mean age was $4.47 \pm 0.67$ years. Most preschool-aged children were from medium SEP families (39.5\%), followed by high (38.0\%) and low SEP (22.5\%). A total of 6570 children aged 6 to 10 years old were observed; $50.3 \%$ were males and the mean age was $7.94 \pm 1.35$ years. Most children were from high $(37.5 \%)$ or medium SEP families (36.9\%)
(Table 1). Daily total screen time was higher during the weekend than the weekdays, both for younger - 183.15 $\mathrm{min} /$ day (95\% Confidence Interval: 177.55-188.74) and $97.59 \mathrm{~min} /$ day (95\% CI: 93.77-101.40), respectively - and older children - $251.61 \mathrm{~min} /$ day (95\% CI: 247.10 256.12) and $99.91 \mathrm{~min} /$ day (95\% CI: 97.07-102.75), respectively (data not shown).

Figures 1 and 2 shows the frequency of weekly use (weekdays plus Saturday plus Sunday) by children's age and according to their gender and SEP. In comparison with other devices, screen time allocated to TV was the highest, independently of children's age, remained almost constant across all age groups, and extremely high since a young age. Among girls, the time allocated for computer increased rapidly across ages, while for boys, the most rapidly increase was found for electronic game devices followed by computer. Boys, compared to girls, spent significantly more minutes per day using screen media devices $(p<0.001)$ and differences according to gender are bigger among older children. Overall, socioeconomic disadvantaged children spent significantly more time per day using screen devices than children from medium and high SEP and the screen time of children from medium SEP was more similar with their counterparts from lower SEP than from high SEP. Screen time was progressively higher among older children, primarily driven by more time spent on electronic devices such as computers, electronic video games and tablets.

The linear regression shows that SEP was a negative predictor of screen time, meaning that children from higher SEP were more likely to spend less minutes per day using screen media devices compared with socioeconomic disadvantaged children (Tables 2 and 3). However, for most media devices, SEP lost is significantly association when adjusted for confounding variables

Table 1 Sample characteristics of Portuguese children participating in the study $(2016 / 2017, n=8430)$

\begin{tabular}{lllll}
\hline & N (\%) & 3-5 years & $6-10$ years & $p$-value \\
\hline Age & & & & \\
3-5 years & $2397(28.4)$ & N.A. & N.A. & N.A. \\
6-10 years & $6033(71.6)$ & N.A. & N.A. & N.A. \\
Gender & & & & \\
$\quad$ Males & $4280(50.8)$ & $1238(51.6)$ & $3042(50.4)$ & 0.30 \\
Females & $4150(49.2)$ & $1159(48.4)$ & $2991(49.6)$ & \\
SEP & & & & \\
Low & $1800(24.9)$ & $476(22.6)$ & $1324(25.9)$ & 0.01 \\
Medium & $2705(37.5)$ & $813(38.6)$ & $1892(37.0)$ & \\
High & $2714(37.6)$ & $817(38.8)$ & $1897(37.1)$ & \\
\hline
\end{tabular}

Legend. SES: socioeconomic position was calculated by father education level low (less than 9 years), medium (10 to 12 years), high (university degree); $p$ values calculated by Chi-Square Tests 


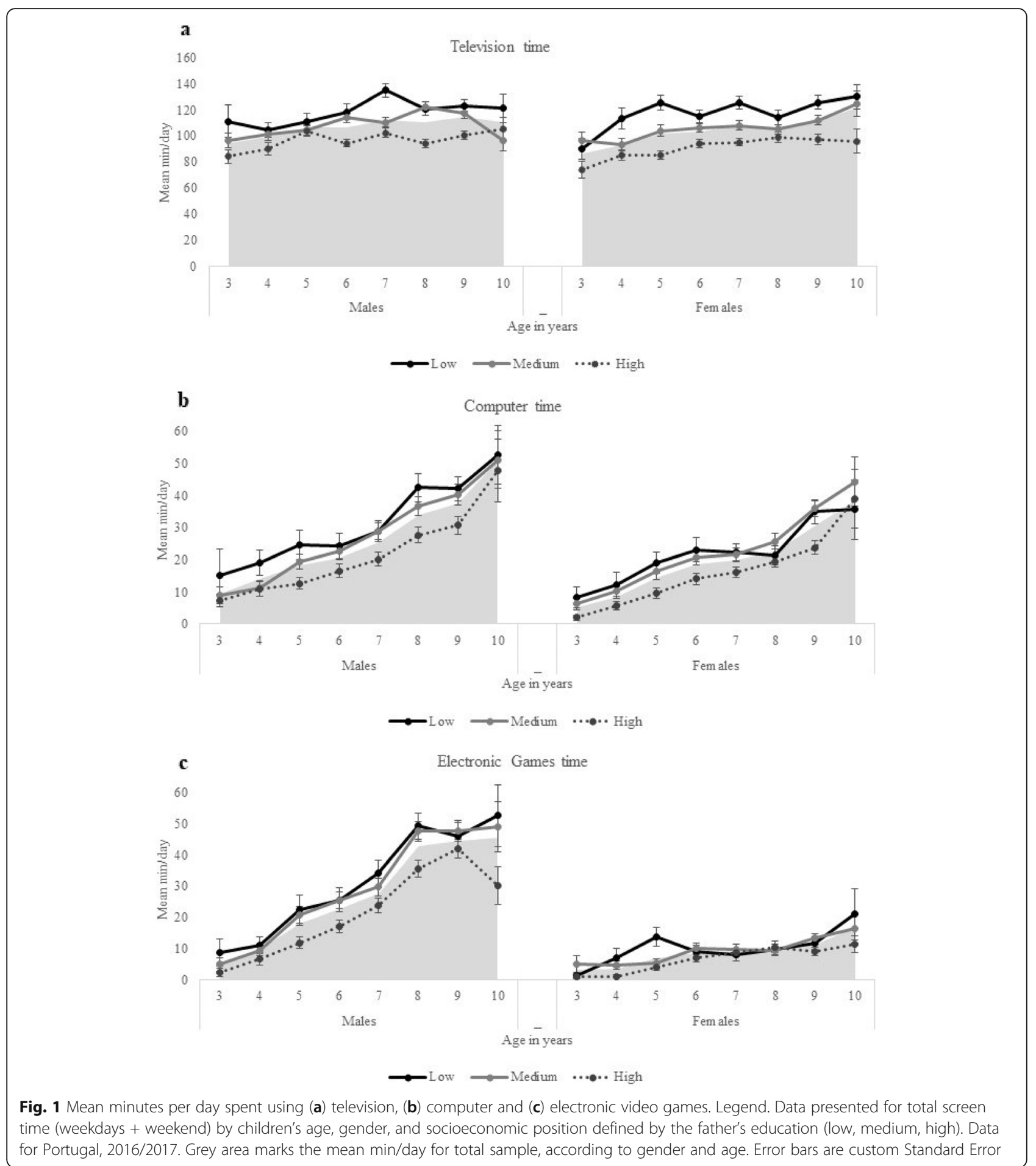

such as mother education, parental occupation and urbanization. SEP was particularly associated with children's screen time on weekends than during weekdays. Independently of the age, 4 to $8 \%$ of the variance (in the final model) in children's screen time was explained by the SEP.
Figure 3 illustrates the prevalence of screen time by 3 categories. Most children aged 3 to 5 exceed the screen time recommendations (e.g., $\geq 60 \mathrm{~min} /$ day) both during the weekdays (73.1\%) and the weekend (93.7\%). One in three children aged 6 to 10 years spent $2 \mathrm{~h} / \mathrm{d}$ or more during school days using screen media devices and $88 \%$ 


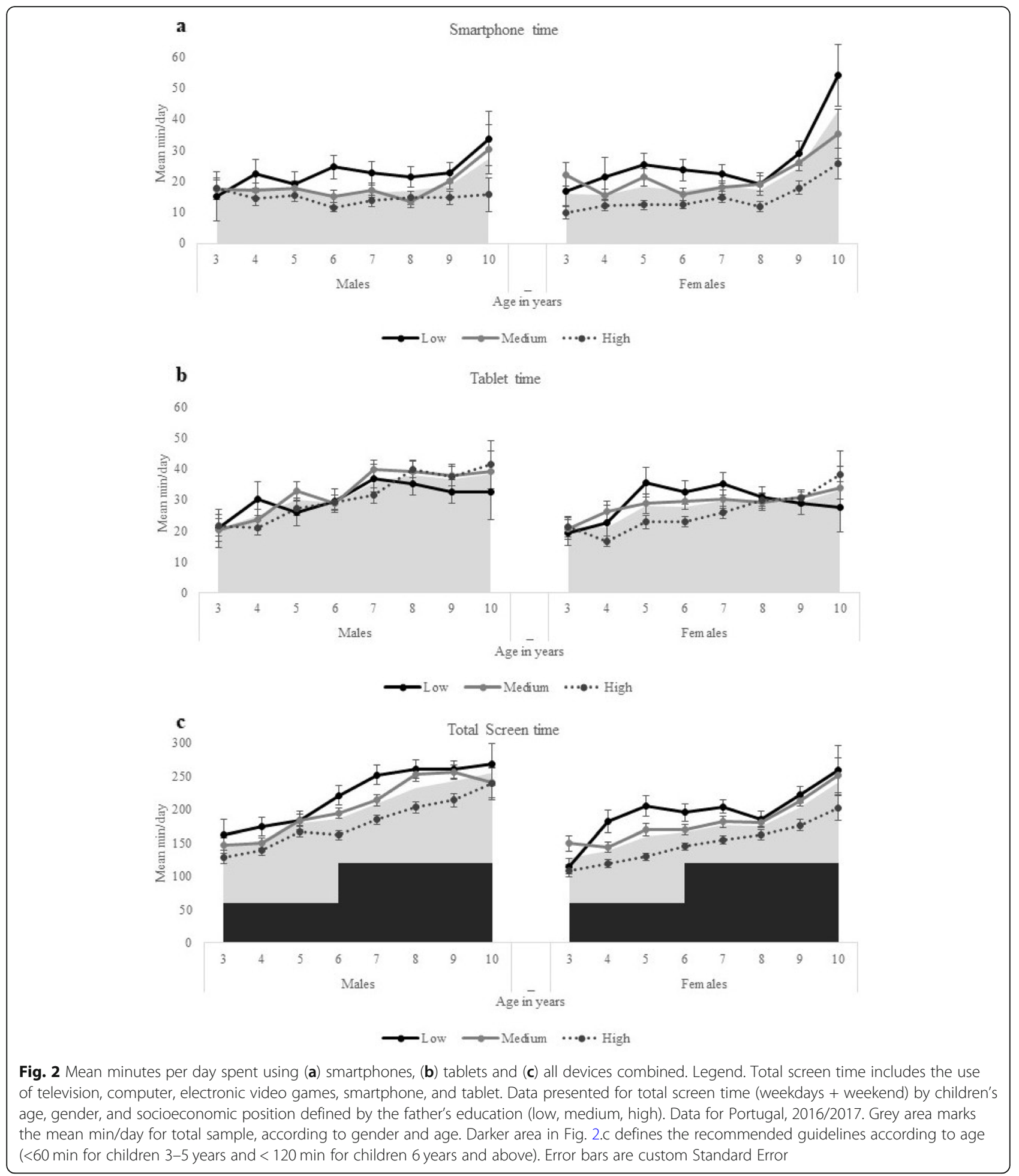

exceed that recommendation during the weekend. Television alone accounted for the most screen time with most children spending more than $1 \mathrm{~h} / \mathrm{d}$ using that device, particularly during the weekend $(82.2$ and $90.3 \%$ for younger and older children, respectively). The prevalence of $<1 \mathrm{~h}$ daily TV viewing, PC and electronic video games use was significantly lower in older children compared with the ones aged 3 to 5 years $(p<0.001)$ for both weekdays and weekend. The prevalence of $\geq 1 \mathrm{~h} / \mathrm{d}$ using tablets and smartphones was significantly higher among older children, compared with their younger counterparts, but differences were only found for the weekend. 
Table 2 Linear regression models predicting screen time according to socioeconomic position, children aged 3-5 years

\begin{tabular}{|c|c|c|c|c|c|c|c|c|c|}
\hline & \multicolumn{3}{|l|}{ Model 1} & \multicolumn{3}{|l|}{ Model 2} & \multicolumn{3}{|l|}{ Model 3} \\
\hline & $\bar{B}$ & $95 \% \mathrm{Cl}$ & $R^{2}$ & $\bar{B}$ & $95 \% \mathrm{Cl}$ & $R^{2}$ & $\bar{B}$ & $95 \% \mathrm{Cl}$ & $R^{2}$ \\
\hline \multicolumn{10}{|c|}{ Television time (mean/day) } \\
\hline Weekdays & $-5.31^{* *}$ & $-8.31 ;-2.31$ & 0.006 & $-5.31^{* *}$ & $-8.21 ;-2.31$ & 0.007 & 1.40 & $-2.74 ; 5.55$ & 0.019 \\
\hline Weekend & $-13.27^{* * *}$ & $-17.37 ;-9.24$ & 0.021 & $-13.30^{* * *}$ & $-17.37 ;-9.24$ & 0.028 & -3.21 & $-8.80 ; 2.38$ & 0.042 \\
\hline \multicolumn{10}{|c|}{ Computer time (mean/day) } \\
\hline Weekdays & $-2.50^{* * *}$ & $-3.76 ;-1.24$ & 0.008 & $-2.49^{* * *}$ & $-3.74 ;-1.24$ & 0.021 & -0.56 & $-2.30 ; 1.18$ & 0.025 \\
\hline Weekend & $-5.80^{* * *}$ & $-7.86 ;-3.74$ & 0.017 & $-5.78^{* * *}$ & $-7.82 ;-3.74$ & 0.040 & -1.77 & $-4.59 ; 1.06$ & 0.048 \\
\hline \multicolumn{10}{|c|}{ Electronic Games time (mean/day) } \\
\hline Weekdays & $-2.02^{* * *}$ & $-3.00 ;-1.03$ & 0.009 & $-2.02^{* * *}$ & $-2.99 ;-1.05$ & 0.037 & -0.71 & $-2.06 ; 0.63$ & 0.041 \\
\hline Weekend & $-4.13^{* * *}$ & $-6.00 ;-2.26$ & 0.010 & $-4.10^{* * *}$ & $-5.92 ;-2.28$ & 0.061 & -1.90 & $-4.41 ; 0.62$ & 0.065 \\
\hline \multicolumn{10}{|c|}{ Smartphone time (mean/day) } \\
\hline Weekdays & $-2.69^{* * *}$ & $-4.15 ;-1.23$ & 0.007 & $-2.69^{* * *}$ & $-4.16 ;-1.23$ & 0.006 & -0.78 & $-2.80 ; 1.25$ & 0.014 \\
\hline Weekend & $-4.15^{* * *}$ & $-6.30 ;-2.01$ & 0.008 & $-4.16^{* * *}$ & $-6.31 ;-2.01$ & 0.008 & -0.78 & $-3.75 ; 2.18$ & 0.020 \\
\hline \multicolumn{10}{|c|}{ Tablet time (mean/day) } \\
\hline Weekdays & $-1.86^{*}$ & $-3.53 ;-0.19$ & 0.002 & $-1.86^{*}$ & $-3.53 ;-0.20$ & 0.003 & -1.99 & $-4.30 ; 0.32$ & 0.002 \\
\hline Weekend & $-3.07^{*}$ & $-5.70 ;-0.43$ & 0.002 & $-3.11^{*}$ & $-5.73 ;-0.49$ & 0.011 & -1.97 & $-5.60 ; 1.66$ & 0.013 \\
\hline \multicolumn{10}{|c|}{ Total screen weekdays (mean/day) } \\
\hline & $-11.51^{* * *}$ & $-16.80 ;-6.22$ & 0.010 & $-11.46^{* * *}$ & $-16.74 ;-6.17$ & 0.012 & -4.26 & $-11.51 ; 3.00$ & 0.020 \\
\hline \multicolumn{10}{|c|}{ Total screen weekend (mean/day) } \\
\hline & $-24.66^{* * *}$ & $-32.30 ;-17.01$ & 0.023 & $-24.55^{* * *}$ & $-32.16 ;-16.93$ & 0.030 & $-12.71^{*}$ & $-23.10 ;-2.31$ & 0.043 \\
\hline \multicolumn{10}{|c|}{ Total screen 7 days (mean/day) } \\
\hline & $-19.60^{* * *}$ & $-26.03 ;-13.17$ & 0.021 & $-19.50^{* * *}$ & $-25.91 ;-13.09$ & 0.027 & $-9.59^{* *}$ & $-18.33 ;-0.85$ & 0.041 \\
\hline
\end{tabular}

Legend. B: Unstandardized beta coefficient; $95 \%$ Cl: $95 \%$ confidence interval; $R^{2}$ : adjusted R-square; socioeconomic position calculated by father education; Model 1: crude, Model 2: adjusted for children's gender, Model 3: like model 2 plus mother education, parental occupation and urbanization; * $p<0.05$,

${ }^{* *} p<0.01,{ }^{* * *} p<0.001$

\section{Discussion}

This study describes the patterns of use of electronic devices in Portuguese young children, according to their gender, age and SEP, measured by father education. Rapid advancements and increased ownership of information and communications technology in recent years has increased the variety of screen-based media available to young people however, present findings show that TV viewing remains the predominant source of children's electronic media use. This is consistent with results from other countries like the United States $[4,7,36]$ and the United Kingdom [37].

At age 3, children were already using screen base devices on a daily basis and the time spent on screen devices progressively increased with age. This age-related increase in screen time has been commonly reported [37]. However, TV time was already high among 3 and 4 years old children, occupying approximately 91 and 96 min per day, respectively. TV time was similar or even higher than the ones reported in the last decades, before the advent of mobile devices [7, 38, 39] which increases concerns on excessive screen time and potential harmful effects on children's health [40], given that, the increasingly popularity of new technologies (i.e., tablets and smartphones) are being added to daily traditional screens use (i.e., TV and PC). Chen and Adler (2019) reported a similar pattern in which screen time doubled among children aged 0 to 2 years, from 1997 to 2014, mainly because young children's TV time did not decrease after the advent of mobile devices [7].

Tablet was the second equipment that consumed more time from children, independently of their age group, gender, and SEP, which is consistent with the latest screen media report carried out in 3-4 and 5-15 years old children from the United Kingdom [41]. Also, a study from North America, found that most children had their own tablet by age 4 and that by age 2, 3 out of 4 children were using mobile devices on a daily basis [8]. Increase ownership and patterns of use suggest that mobile devices, more specifically tablets, may displace TV as major sources of media consumption for young children in the years to come. However, tablets may not be very different from TV, given that a previous study found that photo and video viewing were the most common activities performed on touch-screen devices [42]. In this case, some of the issues that arise with passive 
Table 3 Linear regression models predicting screen time according to socioeconomic position, children aged 6-10 years

\begin{tabular}{|c|c|c|c|c|c|c|c|c|c|}
\hline & \multicolumn{3}{|l|}{ Model 1} & \multicolumn{3}{|l|}{ Model 2} & \multicolumn{3}{|l|}{ Model 3} \\
\hline & $\mathrm{B}$ & $95 \% \mathrm{Cl}$ & $R^{2}$ & $\mathrm{~B}$ & $95 \% \mathrm{Cl}$ & $R^{2}$ & $\mathrm{~B}$ & $95 \% \mathrm{Cl}$ & $R^{2}$ \\
\hline \multicolumn{10}{|c|}{ Television time (mean/day) } \\
\hline Weekdays & $-8.76^{* * *}$ & $-10.61 ;-6.91$ & 0.020 & $-8.76^{* * *}$ & $-10.61 ;-6.91$ & 0.020 & -1.57 & $-4.16 ; 1.02$ & 0.047 \\
\hline Weekend & $-15.21^{* * *}$ & $-17.77 ;-12.65$ & 0.031 & $-15.06^{* * *}$ & $-17.63 ;-12.50$ & 0.032 & $-4.06^{*}$ & $-7.64 ;-0.49$ & 0.057 \\
\hline \multicolumn{10}{|c|}{ Computer time (mean/day) } \\
\hline Weekdays & $-2.34^{* * *}$ & $-3.35 ;-1.33$ & 0.005 & $-2.13^{* * *}$ & $-3.13 ;-1.12$ & 0.019 & 0.21 & $-1.20 ; 1.61$ & 0.031 \\
\hline Weekend & $-6.94^{* * *}$ & $-8.84 ;-5.05$ & 0.012 & $-6.37^{* * *}$ & $-8.24 ;-4.50$ & 0.047 & -1.66 & $-4.27 ; 0.95$ & 0.059 \\
\hline \multicolumn{10}{|c|}{ Electronic Games time (mean/day) } \\
\hline Weekdays & $-1.87^{* * *}$ & $-2.80 ;-0.94$ & 0.004 & $-1.73^{* * *}$ & $-2.65 ;-0.82$ & 0.045 & 0.66 & $-0.62 ; 1.95$ & 0.055 \\
\hline Weekend & $-4.10^{* * *}$ & $-5.99 ;-2.20$ & 0.004 & $-3.72^{* * *}$ & $-5.49 ;-1.95$ & 0.137 & -0.24 & $-2.73 ; 2.26$ & 0.143 \\
\hline \multicolumn{10}{|c|}{ Smartphone time (mean/day) } \\
\hline Weekdays & $-2.56^{* * *}$ & $-3.53 ;-1.60$ & 0.006 & $-2.41^{* * *}$ & $-3.38 ;-1.45$ & 0.011 & 0.06 & $-1.28 ; 1.41$ & 0.024 \\
\hline Weekend & $-5.87^{* * *}$ & $-7.47 ;-4.27$ & 0.012 & $-5.56^{* * *}$ & $-7.16 ;-3.96$ & 0.019 & -0.98 & $-3.22 ; 1.26$ & 0.034 \\
\hline \multicolumn{10}{|c|}{ Tablet time (mean/day) } \\
\hline Weekdays & -0.71 & $-1.88 ; 0.47$ & 0.000 & -0.63 & $-1.81 ; 0.55$ & 0.001 & 0.26 & $-1.40 ; 1.93$ & 0.005 \\
\hline Weekend & -1.71 & $-3.70 ; 0.28$ & 0.000 & -1.58 & $-3.56 ; 0.41$ & 0.008 & $-3.12^{*}$ & $-5.94 ;-0.30$ & 0.009 \\
\hline \multicolumn{10}{|c|}{ Total screen weekdays (mean/day) } \\
\hline & $-14.91^{* * *}$ & $-18.80 ;-11.02$ & 0.015 & $-14.95^{* * *}$ & $-18.84 ;-11.07$ & 0.017 & -1.50 & $-6.92 ; 3.91$ & 0.042 \\
\hline \multicolumn{10}{|c|}{ Total screen weekend (mean/day) } \\
\hline & $-33.34^{* * *}$ & $-39.46 ;-27.22$ & 0.029 & $-33.63^{* * *}$ & $-39.67 ;-27.58$ & 0.053 & $-13.97^{* *}$ & $-22.44 ;-5.51$ & 0.073 \\
\hline \multicolumn{10}{|c|}{ Total screen 7 days (mean/day) } \\
\hline & $-27.81^{* * *}$ & $-32.81 ;-22.82$ & 0.032 & $-27.97^{* * *}$ & $-32.92 ;-23.03$ & 0.051 & $-9.97^{* *}$ & $-16.87 ;-3.07$ & 0.076 \\
\hline
\end{tabular}

Legend. B: Unstandardized beta coefficient; $95 \%$ Cl: $95 \%$ confidence interval; $R^{2}$ : adjusted R-square; socioeconomic position calculated by father education; Model 1: crude, Model 2: adjusted for children's gender, Model 3: like model 2 plus mother education, parental occupation and urbanization; * $p<0.05$,

${ }^{* *} p<0.01,{ }^{* * *} p<0.001$

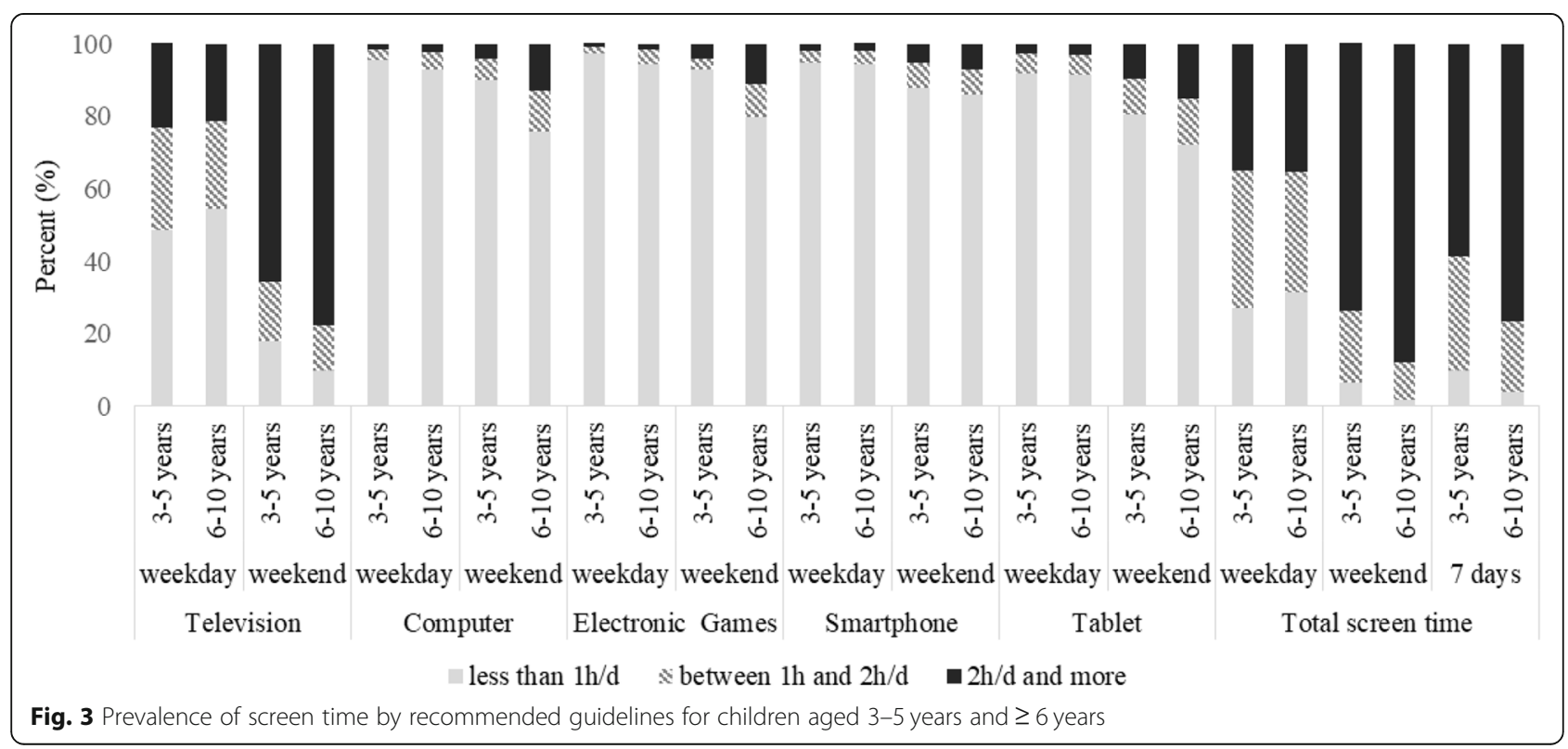


watching TV still apply such as, exposure to unsuitable material, passive eating, increased consumption of energy-dense foods and sugar-sweetened beverages, and displacement of other developmentally important activities $[43,44]$.

Another emerging device, the smartphone, was extremely common, surpassing the use of computers and electronic video game devices among the youngest children. Latest findings show that household ownership of tablets and smartphones doubled in the last decade, including within preschool children $[4,8]$ which may help to explain present results. Frequent mobile device use is likely to increase children's social isolation, and hinder opportunities for social interaction with family and friends [45].

In aggregate, the total screen time reported for many of these children, including the young ones, exceed previous recommendations to limit daily screen time to less than 1 or $2 \mathrm{~h}[21,22]$. In this sample, more than $90 \%$ of children spent more than $1 \mathrm{~h}$ /day using screen media devices. Moreover, close to $77 \%$ of children aged 6 years and above use media devices for $2 \mathrm{~h}$ or more on a daily basis which can significantly reduce the physical and psychosocial health [30, 31, 46]. These findings are in line with previous analysis that demonstrated widespread usage of screen-based media in young people living in a variety of European countries, United States, Brazil and Australia, in which at least two thirds of 4 to 17 years old children exceeded $2 \mathrm{~h} /$ day of screen time [27, 47]. Similarly, data collected in 2002/2003 among Portuguese children aged 7-9 years showed that approximately $70 \%$ spent more than $2 \mathrm{~h}$ /day watching TV, which was the most predominant sedentary behavior followed by electronic games and computer use [38].

Consistent with other studies we found that screen time activities differed between boys and girls [23, 47]. Of all the activities covered in this study, gaming had the biggest gender disparity: boys in each age group spend more minutes than girls in a typical week playing games. The same tendency was recently reported for British pre-school and school-aged children [41]. Also, differences by gender increased between age groups and the higher levels of screen viewing by older children could be at least partially explained by increased use of computers and electronic video games $[48,49]$.

The family SEP was significantly associated with screen time, even after adjusting for confounders, and the disparities were similar to previous studies that found inverse associations between SEP and screenbased media use $[7,47,50,51]$. SEP explained between 4 to $8 \%$ of the variance in children's screen time which is consistent with the work of Carson and Janssen, [52] where family demographic explained approximately $8 \%$ of the variance in screen time among Canadian children aged $0-5$ years. Generally, the results indicate that socioeconomic disadvantaged children spent, in average, more time using media devices compared with children from higher SEP. Moreover, in most devices, the results for medium SEP children were more closely related with the ones from low SEP children than with their counterparts from higher SEP. Decreasing costs and marketing strategies can explain the access to screen devices by all SEP groups. In addition, it might be possible that parents from more educated backgrounds set limits when children use screen devices. Other studies have shown that a lower parental education is associated with lower parental modeling, less parental co-viewing, more chance to have a TV in the bedroom and to eat meals in front of the TV [53]. Other possible explanation is that poorer children may spend more time indoors due to a greater likelihood of living in unsafe neighborhoods [54].

The difference in screen media use between lower vs. higher SEP was found between all ages but the gap was even larger in older than in younger children, particularly in some devices like electronic games and smartphones. Present findings suggest the need to intervene at different stages of childhood, starting in young ages, in order to decrease specific screen time behaviors. Physicians and other health care providers should counsel parents and caregivers of young children on the appropriate use of screen time.

Strengths include the large sample size collected at a national level in pre-school aged and schools aged children. In addition, the screen time was obtained for all of the electronic devices, including traditional and emerging/mobile devices such as tablets and smartphones. The survey assessed weekday as well as Saturday and Sunday screen time and the study took both time periods in consideration. Also this was one of the first studies to date to examine screen time in traditional and emerging devices in young children according to the SEP. Limitations of the study include the cross sectional design which makes us unable to draw cause-effect conclusions and to make observations over the time. In addition, since it is not feasible to obtain direct measurements of screen time in large population-based studies, the screen time measures were parental-reported. The information bias associated with these measures may have resulted in an underestimation of screen time.

\section{Conclusions}

This study shows that screen time in children aged 3 to 10 years, is longer than the recommended, particularly among boys, that children engage in these activities starting at a young age and increases in screen-based entertainment use occurs from younger to older children. Moreover, SEP explained some of the variance in 
children's screen time, with screen time being higher in socioeconomic disadvantaged children. Effective strategies targeting children and/or their parents are needed to equitably reduce unhealthy behaviors among children.

\section{Abbreviations}

SEP: Socioeconomic position; TV: Television; PC: Computer; EG: Electronic games; d: Day; h: Hour(s); min: Minutes; SE: Standard error; Cl: Confidence interval; AAP: American Academy of Pediatrics

\section{Acknowledgements}

We thank all the children, parents and school staff for their availability to participate during the data collection.

\section{Authors' contributions}

DR conceived the study aim, analyzed and interpreted the data and drafted the article. AG, AM-R, VR, M-RS, HN and CP designed the original study, developed the study methodology, acquired the data and critically revised the manuscript. All authors approved the final manuscript as submitted and agree to be accountable for all aspects of the work.

\section{Funding}

This study was financially supported by Fundação para a Ciência e Tecnologia (Portugal) through grant PTDC/DTP-SAP/1520/2014, with funds from the COMPETE 2020, Portugal 2020, FEDER and FCT. The funders had no role in the design, data collection and analysis, decision to publish, or preparation of the manuscript.

\section{Availability of data and materials}

The datasets generated during the current study are available from the corresponding author on request.

\section{Ethics approval and consent to participate}

Prior to commencing the study, the protocol was approved by Direção Geral do Ensino (Portuguese Ministry of Education) and Comissão Nacional de Proteção de Dados (CNPD), the Portuguese Data Protection Authority (Authorization number 745/2017). All procedures were in accordance with the 1964 Helsinki declaration and its later amendments. Written informed consent was obtained from children's parents.

\section{Consent for publication}

Not applicable.

\section{Competing interests}

Aristides M. Machado-Rodrigues is an Editorial Board Member. The remained authors have indicated they have no potential conflicts of interest to disclose and that they have no financial relationships relevant to this article to disclose.

\section{Author details}

${ }^{1} \mathrm{CIAS}$ - Research Centre for Anthropology and Health, University of Coimbra, Ed. São Bento, Calçada Martim de Freitas, 3000-456 Coimbra, Portugal. 2Department of Life Sciences, University of Coimbra, Coimbra, Portugal. ${ }^{3}$ Department of Animal Biology, Faculty of Sciences of the University of Lisbon, Lisbon, Portugal. ${ }^{4}$ High School of Education, Polytechnic Institute of Viseu, Viseu, Portugal. ${ }^{5}$ Faculty of Health Sciences, University Fernando Pessoa, Porto, Portugal. ${ }^{6}$ Faculty of Human Kinetics, University of Lisbon, Lisbon, Portugal.

Received: 17 October 2019 Accepted: 1 June 2020

\section{Published online: 10 June 2020}

\section{References}

1. American Academy of Pediatrics. Children, adolescents, and the media. Pediatrics. 2013;132(5):958-61. https://doi.org/10.1542/peds.2013-2656.

2. Connell SL, Lauricella AR, Wartella E. Parental co-use of media technology with their young children in the USA. J Child Media. 2015;9:5-21. https:// doi.org/10.1080/17482798.2015.997440.

3. Canadian Paediatric Society, Digital Health Task Force, Ottawa, Ontario. Screen time and young children: promoting health and development in a digital world. Paediatr Child Health. 2017;22(8):461-77. https://doi.org/10. 1093/pch/pxx123.

4. Rideout $\mathrm{V}$. The common sense census: media use by kids age zero to eight, report. San Francisco: Common Sense Media; 2017. https://www. commonsensemedia.org/sites/default/files/uploads/research/census_ researchreport.pdf. Accessed 14 Oct 2019.

5. Magee CA, Lee JK, Vella SA. Bidirectional relationships between sleep duration and screen time in early childhood. JAMA Pediatr. 2014;168(5):46570. https://doi.org/10.1001/jamapediatrics.2013.4183.

6. Chassiakos YR, Radesky J, Christakis D, Moreno MA, Cross C. Children and adolescents and digital media. Pediatrics. 2016;138(5):e201625936. https:// doi.org/10.1542/peds.2016-2593.

7. Chen W, Adler JL. Assessment of screen exposure in young children, 1997 to 2014. JAMA Pediatr. 2019;173(4):391-3. https://doi.org/10.1001/ jamapediatrics.2018.5546.

8. Kabali HK, Irigoyen MM, Nunez-Davis R, Budacki JG, Mohanty SH, Leister KP, Bonner RL. Exposure and use of Mobile media devices by young children. Pediatrics. 2015;136(6):1044-50. https://doi.org/10.1542/peds.2015-2151.

9. Salmon J, Tremblay MS, Marshall SJ, Hume C. Health risks, correlates, and interventions to reduce sedentary behavior in young people. Am J Prev Med. 2011:41:197-206. https://doi.org/10.1016/j.amepre.2011.05.001.

10. Hinkley T, Verbestel V, Ahrens W, Lissner L, Molnár D, Moreno LA, Pigeot I, Pohlabeln H, Reisch LA, Russo P, Veidebaum T, Tornaritis M, Williams G, De Henauw S, De Bourdeaudhuij I, for the IDEFICS Consortium. Early childhood electronic media use as a predictor of poorer well-being. A prospective cohort study. JAMA Pediatr. 2014;168(5):485-92. https://doi.org/10.1001/ jamapediatrics.2014.94

11. Lissak G. Adverse physiological and psychological effects of screen time on children and adolescents: literature review and case study. Environ Res. 2018;164:149-57. https://doi.org/10.1016/j.envres.2018.01.015.

12. Fang K, Mu M, Liu K, He Y. Screen time and childhood overweight/obesity: a systematic review and meta-analysis. Child Care Health Dev. 2019;45(5): 744-53. https://doi.org/10.1111/cch.12701.

13. Börnhorst $C$, Wijnhoven TM, Kunešová $M$, Yngve $A$, Rito Al, Lissner L, Duleva $\checkmark$, Petrauskiene A, Breda J. WHO European childhood obesity surveillance initiative: associations between sleep duration, screen time and food consumption frequencies. BMC Public Health. 2015;15:442. https://doi.org/ 10.1186/s12889-015-1793-3.

14. Dworak M, Schierl T, Bruns T, Strüder HK. Impact of singular excessive computer game and television exposure on sleep patterns and memory performance of school-aged children. Pediatrics. 2007;120(5):978-85. https:// doi.org/10.1542/peds.2007-0476.

15. Madigan S, Browne D, Racine N. Association between screen time and children's performance on a developmental screening test. JAMA Pediatr. 2019;173(3):244-50. https://doi.org/10.1001/jamapediatrics.2018.5056.

16. Tamana SK, Ezeugw V, Chikuma J, Lefebvre DL, Azad MA, Moraes TJ, et al. Screen-time is associated with inattention problems in preschoolers: results from the CHILD birth cohort study. PLoS One. 2019;14(4):e0213995. https:// doi.org/10.1371/journal.pone.0213995.

17. Twenge JM, Campbell WK. Associations between screen time and lower psychological well-being among children and adolescents: evidence from a population-based study. Prev Med Rep. 2018;12:271-83. https://doi.org/10. 1016/.j.pmedr.2018.10.003.

18. Domoff SE, Borgen AL, Foley RP, Maffett A. Excessive use of mobile devices and children's physical health. Hum Behav Emerging Technol. 2019:1:16975. https://doi.org/10.1002/hbe2.145.

19. Elhai JD, Dvorak RD, Levine JC, Hall BJ. Problematic smartphone use: a conceptual overview and systematic review of relations with anxiety and depression psychopathology. J Affect Disord. 2017;207:251-9. https://doi. org/10.1016/j.jad.2016.08.030.

20. Elhai JD, Levine JC, Hall BJ. The relationship between anxiety symptom severity and problematic smartphone use: a review of the literature and conceptual frameworks. J Anxiety Disord. 2019;62:45-52. https://doi.org/10. 1016/j.janxdis.2018.11.005.

21. American Academy of Pediatrics. American Academy of Pediatrics announces new recommendations for children's media use. 2016. https:// www.aap.org/en-us/about-the-aap/aap-press-room/Pages/AmericanAcademy-of-Pediatrics-Announces-New-Recommendations-for-ChildrensMedia-Use.aspx. Accessed 22 May 2019.

22. WHO - World Health Organization. Guidelines on physical activity, sedentary behaviour and sleep for children under 5 years of age. World 
Health Organization. https://apps.who.int/iris/handle/10665/311664. Accessed 10 Oct 2019

23. Pate RR, Mitchell JA, Byun W, Dowda M. Sedentary behaviour in youth. Br J Sports Med. 2011;45(11):906-13. https://doi.org/10.1136/bjsports-2011090192

24. Houghton S, Hunter SC, Rosenberg M, Wood L, Zadow C, Martin K, et al. Virtually impossible: limiting Australian children and adolescents daily screen based media use. BMC Public Health. 2015;15:5. https://doi.org/10. 1186/1471-2458-15-5.

25. Chaput J-P, Colley RC, Aubert S, Carson V, Janssen I, Roberts KC, et al. Proportion of preschool-aged children meeting the Canadian 24-hour movement guidelines and associations with adiposity: results from the Canadian health measures survey. BMC Public Health. 2017;17(5):829. https://doi.org/10.1186/s12889-017-4854-y.

26. Paudel S, Jancey J, Subedi N, Leavy J. Correlates of mobile screen media use among children aged 0-8: a systematic review. BMJ Open. 2017;7:e014585. https://doi.org/10.1136/bmjopen-2016-014585.

27. Thomas G, Bennie JA, De Cocker K, Castro O, Biddle SJH. A descriptive epidemiology of screen-based devices by children and adolescents: a scoping review of 130 surveillance studies since 2000. Child Indic Res. 2019. https://doi.org/10.1007/s12187-019-09663-1.

28. Bingham DD, Varela-Silva Ml, Ferrão MM, Gama A, Mourão Ml, Nogueira H, et al. Socio-demographic and behavioral risk factors associated with the high prevalence of overweight and obesity in Portuguese children. Am J Hum Biol. 2013;25(6):733-42. https://doi.org/10.1002/ajhb.22440.

29. Sigmundová D, Sigmund E, Badura P, Vokáčová J, Trhlíková L, Bucksch J. Weekday-weekend patterns of physical activity and screen time in parents and their pre-schoolers. BMC Public Health. 2016;16(1). https://doi.org/10. 1186/s12889-016-3586-8.

30. Tremblay MS, LeBlanc AG, Kho ME, Saunders TJ, Larouche R, Colley RC Systematic review of sedentary behaviour and health indicators in schoolaged children and youth. Int J Nutr Phys Act. 2011;8:98. https://doi.org/10. 1186/1479-5868-8-98.

31. Przybylski AK. Electronic gaming and psychosocial adjustment. Pediatrics. 2014;134(3):e716-22. https://doi.org/10.1542/peds.2013-4021.

32. INE, Instituto Nacional de Estatística / National Statistics Institute. New classifications of occupations - Portuguese classification of occupations of 2010 (CPP/2010). https://www.ine.pt/xportal/xmain?xpgid=ine_main\&xpid= INE. Accessed 01 Feb 2020.

33. Monteiro JL. Caracterização dos espaços urbanos na RLVT: o contributo da análise discriminante. Revista de Estudos Regionais - Instituto Nacional de Estatística. 2000;2(1):21-46.

34. Mota J, Santos R, Pereira M, Teixeira L, Santos MP. Perceived neighbourhood environmental characteristics and physical activity according to socioeconomic status in adolescent girls. Ann Hum Biol. 2011;38(1):1-6. https://doi.org/10.3109/03014460.2010.486769.

35. Machado-Rodrigues AM, Valente-dos-Santos J, Fernandes R, Gama A, Mourao I, Nogueira H, et al. Waist-to-height ratio and its association with TV viewing in a sample of Portuguese children aged 7-9 years. Am J Hum Biol. 2017;29(5). https://doi.org/10.1002/ajhb.23024.

36. Rideout VJ, Foehr UG, Roberts DF. "Generation M": media in the lives of 8-18 year olds. Kaiser Family Foundation Study 2010. https://files.eric.ed.gov/ fulltext/ED527859.pdf. Accessed 20 Sep 2019.

37. Basterfield L, Adamson AJ, Frary JK, Parkinson KN, Pearce MS, Reilly JJ. Longitudinal study of physical activity and sedentary behavior in children. Pediatrics. 2011;127:e24-30. https://doi.org/10.1542/peds.2010-1935.

38. Carvalhal MM, Padez C, Moureira PA, Rosado VM. Overweight and obesity related to activities in Portuguese children, 7-9 years. Eur J Pub Health. 2007; 174(1):42-6. https://doi.org/10.1093/eurpub/ckl093.

39. Jago R, Stamatakis E, Gama A, Carvalhal IM, Nogueira H, Rosado V, et al. Parent and child screen-viewing time and home media environment. Am J Prev Med. 2012;43(2):150-8. https://doi.org/10.1016/j.amepre.2012.04.012.

40. Stiglic N, Viner RM. Effects of screentime on the health and well-being of children and adolescents: a systematic review of reviews. BMJ Open. 2019;9: e023191. https://doi.org/10.1136/bmjopen-2018-023191.

41. Ofcom. Children and parents: media use and attitudes report 2018. 2019. https://www.ofcom.org.uk/_data/assets/pdf_file/0024/134907/Childrenand-Parents-Media-Use-and-Attitudes-2018.pdf. Accessed 2 Aug 2019.

42. Cristia A, Seidl A. Parental reports on touch screen use in early childhood. PLoS One. 2015;10:e0128338. https://doi.org/10.1371/journal.pone.0128338.
43. Borghese MM, Tremblay MS, Katzmarzyk PT, Tudor-Locke C, Schuna JM Jr, Leduc $\mathrm{G}$, et al. Mediating role of television time, diet patterns, physical activity and sleep duration in the association between television in the bedroom and adiposity in 10 year-old children. Int J Behav Nutr Phys Act. 2015;12:60. https://doi.org/10.1186/s12966-015-0221-5.

44. Hobbs M, Pearson N, Foster PJ, Biddle SJH. Sedentary behaviour and diet across the lifespan: an updated systematic review. Br J Sports Med. 2015; 49(18):1179-88. https://doi.org/10.1136/bjsports-2014-093754.

45. Hosokawa R, Katsura T. Association between mobile technology use and child adjustment in early elementar school age. PLoS One. 2018;13(7): e0199959. https://doi.org/10.1371/journal.pone.0199959.

46. Padez C, Mourão I, Moreira P, Rosado V. Prevalence and risk factors for overweight and obesity in Portuguese children. Acta Paediatr. 2009;94(11): 1550-7. https://doi.org/10.1080/08035250510042924.

47. Atkin AJ, Sharp SJ, Corder K, van Sluijs EMF, International Children's Accelerometry database (ICAD) collaborators. Prevalence and correlates of screen time in youth: an international perspective. Am J Prev Med. 2014; 47(6):803-7. https://doi.org/10.1016/j.amepre.2014.07.043.

48. Cillero IH, Jago R. Sociodemographic and home environment predictors of screen viewing among Spanish school children. J Public Health. 2011;33(3): 392-402. https://doi.org/10.1093/pubmed/fdq087.

49. LeBlanc AG, Broyles ST, Chaput J-P, Leduc G, Boyer C, Borghese MM, et al. Correlates of objectively measured sedentary time and self-reported screen time in Canadian children. Int J Behav Nutr Phys Act. 2015;12:38. https://doi. org/10.1186/s12966-015-0197-1.

50. De Craemer M, Verloigne M, Ghekiere A, Loyen A, Dargent-Molina P, Brug J, et al. Changes in children's television and computer time according to parental education, parental income and ethinicity: a 6-year longitudinal EYHS study. PLoS One. 2018;13(9):e0203592. https://doi.org/10.1371/journal. pone.0203592.

51. Cillero IH, Jago R. Systematic review of correlates of screen-viewing among young children. Prev Med. 2010;51:3-10. https://doi.org/10.1016/j.ypmed. 2010.04.012

52. Carson V, Janssen I. Associations between factors within the home setting and screen time among children aged 0-5 years: a cross-sectional study. BMC Public Health. 2012;12:539. https://doi.org/10.1186/1471-2458-12-539.

53. Gebremariam MK, Altenburg TM, Lakerveld J, Andersen LF, Stronks K, Chinapaw MJ, et al. Associations between socioeconomic position and correlates of sedentary behaviors among youth: a systematic review. Obes Rev. 2015;16(11):988-1000. https://doi.org/10.1111/obr.12314.

54. Pagani $L S$, Huot $C$. Why are children living in poverty getting fatter? Paediatr Child Health. 2007;15(2):154-61. https://doi.org/10.1093/pch/12.698.

\section{Publisher's Note}

Springer Nature remains neutral with regard to jurisdictional claims in published maps and institutional affiliations.

Ready to submit your research? Choose BMC and benefit from:

- fast, convenient online submission

- thorough peer review by experienced researchers in your field

- rapid publication on acceptance

- support for research data, including large and complex data types

- gold Open Access which fosters wider collaboration and increased citations

- maximum visibility for your research: over $100 \mathrm{M}$ website views per year

At $\mathrm{BMC}$, research is always in progress.

Learn more biomedcentral.com/submissions 